\title{
Accuracy of gas analysis in lung function laboratories
}

\author{
DJ CHINN, Y NARUSE, JE COTES
}

\begin{abstract}
From the Respiration and Exercise Laboratory, University Department of Occupational Health, Newcastle upon Tyne
\end{abstract}

\begin{abstract}
Fifty lung function laboratories in England and Wales analysed test gas mixtures of carbon monoxide and helium. Most of them also analysed mixtures of oxygen and carbon dioxide in nitrogen. The percentage accuracy of the results was within $1 \%$ of the expected value in only $14 \%$ of determinations of carbon monoxide concentration, $28 \%$ for carbon dioxide, $37 \%$ for helium, and $48 \%$ for oxygen. The accuracy of ratios of two concentrations of helium and carbon monoxide was better than that of the individual gas samples. Overall the variation in results between laboratories was wide, the coefficient of variation ranging from about $3 \%$ for analysis of helium to $9 \%$ for carbon dioxide. This variation affected the values calculated for carbon monoxide transfer factor, where $20 \%$ were in error by more than $5 \%$, and for the calculated value of the respiratory exchange ratio, where the interlaboratory coefficient of variation was about $10 \%$. Errors in analysis were due to unsatisfactory calibration of analysers; five oxygen analysers had large zero errors; five carbon monoxide analysers and one helium analyser had notably curvilinear calibration curves. Insufficient information was obtained to ascertain the nature of the errors in analysis of carbon dioxide. Given the improvements in instrumentation, these results are evidence for deterioration in analytical standards in lung function laboratories from the standards of 20 years ago.
\end{abstract}

In 1961 the accuracy of analysis of carbon monoxide in UK lung function laboratories was poor and much worse than for helium, oxygen, or carbon dioxide. ${ }^{12}$ The present study reassesses the position in the light of recently established international standards for accuracy in assessment of lung function ${ }^{34}$; these include the recommendation that gas analysis should be accurate to within $1 \%$ of the measured concentration.

\section{Methods}

Three gas mixtures equivalent to those that might be analysed during measurement of transfer factor (diffusing capacity) by the single breath carbon monoxide method (mixtures A, B, and C) and one that contained carbon dioxide (mixture D) were made up in master cylinders. Two batches (i) and (ii) were prepared; they were of similar but not identical composition. For the master cylinders gases were decanted into canisters containing 5 litres at ambient

Address for reprint requests: Dr DJ Chinn, Respiration and Exercise Laboratory, University Department of Occupational Health, Medical School, Newcastle upon Tyne NE2 4HH.

Accepted 2 September 1985 pressure. Cans were marked with the type of gas they contained. Pulmonary function laboratories in England and Wales that expressed an interest in the study were sent samples of mixtures A, B, and C, with a questionnaire on their gas analysis equipment and procedures for calibration. Laboratories that requested it also received mixture $D$. Laboratories were instructed to calibrate their analysers and perform the analyses in the usual manner, feeding in the gas either direct from the canister or via a small bag, which should have been flushed. The results and the used canisters were to be sent to the "reference laboratory" in Newcastle upon Tyne. Here the gas remaining in the cans was reanalysed with a paramagnetic analyser for oxygen (Servomex, 500A), infrared analysers for carbon monoxide (Analytical Development Co Ltd, model 403B) and carbon dioxide (Analytical Development Co Ltd, model 801D), and a katharometer for helium (PK Morgan Ltd). These analysers were calibrated with gas mixtures prepared with a Wösthoff pump (M300/a); response was linear between zero and the highest concentrations, measurements being within $1 \%$ of expected values. The accuracy of analysis is designated "percentage accuracy" in the following account to distinguish it from absolute gas concentration, which 
is reported as percentage of dry gas. Curvilinearity was assessed as percentage deviation of an observed concentration from that expected on the basis of linearity between zero and the highest recorded concentration (fig, a). Alinearity in excess of $4 \%$ has been reported.

To investigate the practical significance of the results, the gas concentrations reported by laboratories were used to calculate transfer factor (TLCO), Kco, and alveolar volume (VA) on the basis of an inspired volume of 41 and breath holding time of 10 seconds. The respiratory exchange ratio (RER) was calculated on the basis of the simplified relationship RER = $\mathrm{F}, \mathrm{CO}_{2} /\left(0.2093-\mathrm{F}, \mathrm{O}_{2}\right)$, where $\mathrm{F}$ is fractional gas concentration.

Results were reported as means $(\overline{\mathbf{x}})$, standard deviations (SD), and coefficient of variation $(\mathrm{CV}=\mathrm{SD} \times$ $100 / \overline{\mathbf{x}})$. The $5 \%$ level of probability was accepted as significant.

\section{Results}

Fifty seven laboratories expressed an interest in the study; of these, 50 analysed carbon monoxide and helium, 39 analysed oxygen, and 29 carbon dioxide. Three cans leaked (all containing mixture $\mathbf{A}$ ) and in two laboratories the gas was contaminated with air during transfer to the analysers. About half of the returned cans (100 out of 189) contained sufficient gas for reanalysis. The reported results for the two batches of test gases were of similar accuracy, so in the following account the absolute results are those for batch 1 only; the ratios and calculated indices are based on all the returns. For each gas mixture the returned cans contained gas at the same concentration (coefficient of variation $\leqslant 0.6 \%$ ); the concentration was practically identical with that reported by the manufacturer for the corresponding master cylinder. The means of the concentrations reported by laboratories were also effectively correct but the spread of results was wide.

For oxygen $48 \%$ of results met the standard for accuracy (percentage accuracy $<1 \%$ ). The spread between laboratories was inversely related to absolute concentration (coefficient of variation $1.8 \%-5.3 \%$ : table 1). This was due to the returns from five laboratories where the analyser calibration had a zero error in excess of $1 \%$ absolute concentration (fig, $b$ ). In two other laboratories the calibrations showed wide scatter. These analysers were all at least five years old.

For carbon dioxide $28 \%$ of results met the standard for accuracy. The spread between laboratories was very wide (coefficient of variation $8.9 \%$ : table 2 ). No information was obtained on calibration of $\omega$ analysers.

For helium $37 \%$ of individual results met the standard for accuracy. The spread between laboratories was independent of helium concentration (coefficient of variation $3 \%$ : table 3 ). One analyser calibration was alinear $(>4 \%)$. Neglect of the effect of oxygen on the katharometer calibration, however, led to systematic underestimation of the concentration of helium in mixture $\mathrm{C}$; thus, whereas $49 \%$ of concentration ratios for mixture B: mixture A met the standard for accuracy, this was the case for only $22 \%$ of the C:A ratios $(p<0.005$ ). The effect of neglecting the oxygen concentration is illustrated by a numerical example in table 4.

For carbon monoxide $14 \%$ of individual results and $38 \%$ of concentration ratios met the standard for accuracy. The spread between laboratories expressed as coefficient of variation was less for ratios $(2-3 \%)$ than for individual results (3-5\%: table 5). Five carbon monoxide analysers were alinear (see fig, $a$ ).

The values calculated for respiratory exchange ratio, alveolar volume, and transfer factor were on

Table 1 Analysis of mixtures for oxygen

\begin{tabular}{|c|c|c|c|c|c|}
\hline \multirow[t]{2}{*}{ Mixture } & \multicolumn{2}{|c|}{ Concentration (\%) } & \multicolumn{3}{|c|}{ Participants' results (\%) } \\
\hline & Master cylinder & Canisters & Mean & Range & $C V$ \\
\hline $\begin{array}{l}\mathbf{A} \\
\mathbf{B} \\
\mathbf{C} \\
\mathbf{D}\end{array}$ & $\begin{array}{l}17.95 \\
16.50 \\
10.50 \\
14.75\end{array}$ & $\begin{array}{l}17.95 \\
16.56 \\
10.68 \\
14.96\end{array}$ & $\begin{array}{l}17.91 \\
16.40 \\
10.44 \\
14.99\end{array}$ & $\begin{array}{r}17.0-18.4 \\
15.1-16.8 \\
8.6-11.1 \\
14.1-16.4\end{array}$ & $\begin{array}{l}1.8 \\
2.2 \\
5.3 \\
2.9\end{array}$ \\
\hline
\end{tabular}

*Coefficient of variation (CV) $0.3-0.5 \%$.

Table 2 Analysis of mixture containing carbon dioxide

\begin{tabular}{|c|c|c|c|c|c|}
\hline \multirow[t]{2}{*}{ Mixture } & \multicolumn{2}{|c|}{ Concentration (\%) } & \multicolumn{3}{|c|}{ Participants' results (\%) } \\
\hline & Master cylinder & Canisters* & Mean & Range & $\mathrm{CV}$ \\
\hline D & 3.90 & 3.83 & 3.77 & $2.60-4.25$ & 8.9 \\
\hline
\end{tabular}

"Coefficient of variation (CV) $0.4 \%$. 

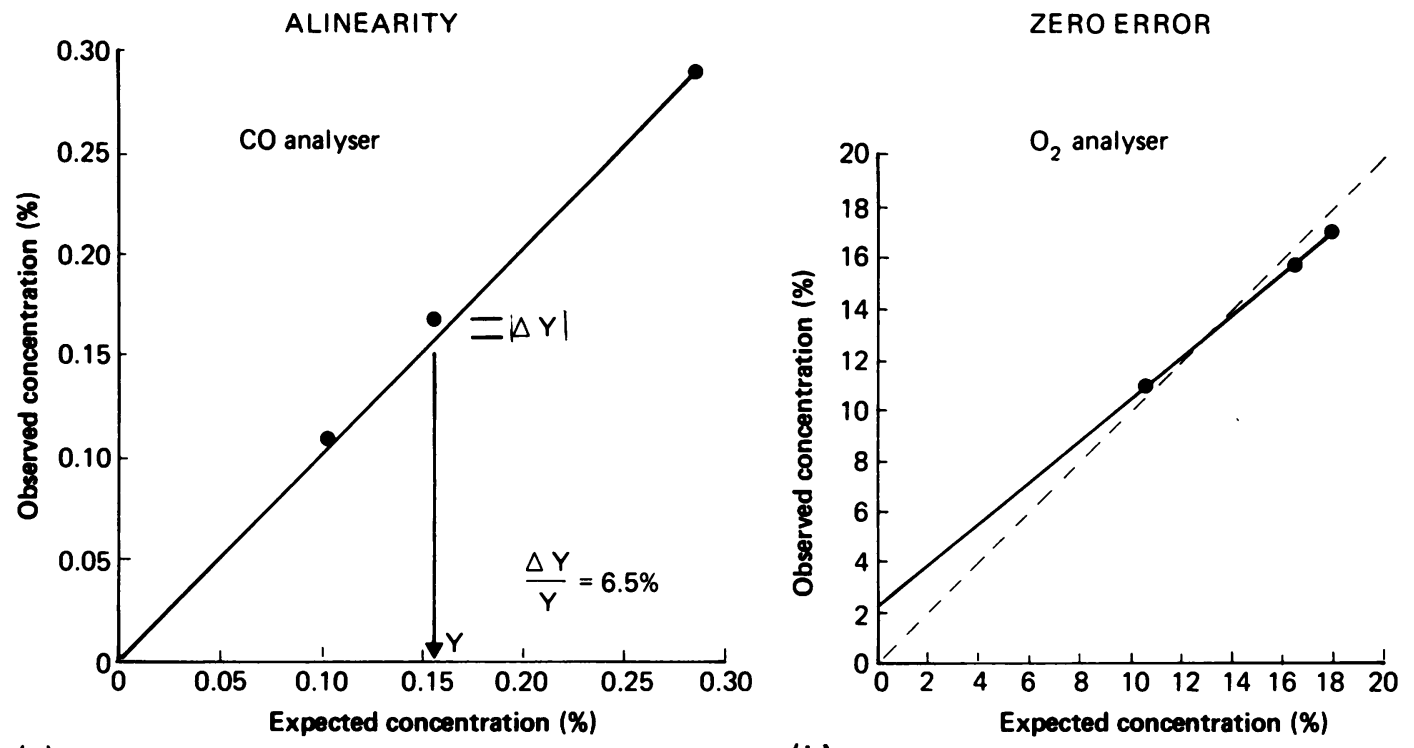

(a)

(b)

Examples of faulty calibration. (a) The continuous line is drawn from the highest recorded concentration to the origin. The alinearity $(\triangle Y / Y)$ is $6.5 \%$. (b) The continuous line is drawn through the recorded concentrations. The line of identity is interrupted. The zero error is over $2 \%$ absolute concentration.

Table 3 Analysis of mixtures for helium

\begin{tabular}{|c|c|c|c|c|c|}
\hline \multirow[t]{2}{*}{ Mixture } & \multicolumn{2}{|c|}{ Concentration (\%) } & \multicolumn{3}{|c|}{ Participants' results (\%) } \\
\hline & Master cylinder & Canisters* & $\overline{\text { Mean }}$ & Range & $C V$ \\
\hline $\begin{array}{l}\mathbf{A} \\
\mathbf{B} \\
\mathbf{C}\end{array}$ & $\begin{array}{r}14.27 \\
10.98 \\
8.41\end{array}$ & $\begin{array}{r}14.09 \\
10.94 \\
8.46\end{array}$ & $\begin{array}{r}14.10 \\
10.87 \\
8.27\end{array}$ & $\begin{array}{c}12.99-14.75 \\
9.80-11.25 \\
7.52-8.65\end{array}$ & $\begin{array}{l}3.0 \\
3.2 \\
3.2\end{array}$ \\
\hline
\end{tabular}

*Coefficient of variation (CV) $0.2 \%$.

Table 4 Error in helium analysis due to neglect of correction for oxygen content*

\begin{tabular}{llll}
\hline & \multicolumn{2}{l}{ Composition (\%) } & Error (\%) \\
\cline { 2 - 4 } Mixture & Helium $\dagger$ & Oxygen & \\
\hline A1 & 14.08 & 18.0 & -0.5 \\
A2 & 13.09 & 18.2 & -0.5 \\
B1 & 10.93 & 16.6 & -0.9 \\
B2 & 10.10 & 15.9 & -1.1 \\
C2 & 8.46 & 10.6 & -2.8 \\
\hline
\end{tabular}

From analysis of one set of canisters in reference laboratory.

tOxygen corrected.

Table 5 Analysis of mixtures for carbon monoxide

\begin{tabular}{|c|c|c|c|c|c|}
\hline \multirow[t]{2}{*}{ Mixture } & \multicolumn{2}{|c|}{ Concentration (\%) } & \multicolumn{3}{|c|}{ Participants' results (\%) } \\
\hline & Master cylinder & Canisters $^{*}$ & Mean & Range & $C V$ \\
\hline $\begin{array}{l}\mathbf{A} \\
\mathbf{B} \\
\mathbf{C}\end{array}$ & $\begin{array}{l}0.282 \\
0.103 \\
0.155\end{array}$ & $\begin{array}{l}0.273 \\
0.099 \\
0.151\end{array}$ & $\begin{array}{l}0.279 \\
0.102 \\
0.155\end{array}$ & $\begin{array}{l}0.258-0.290 \\
0.094-0.117 \\
0.140-0.176\end{array}$ & $\begin{array}{l}3.2 \\
4.6 \\
4.9\end{array}$ \\
\hline
\end{tabular}


average correct. Errors in analysis of oxygen and carbon dioxide, however, led to wide variations between laboratories for the calculated respiratory exchange ratio (coefficient of variation about $10 \%$ : table 6). The variation in single breath alveolar volume calculated from the helium concentration ratio $\mathrm{B}: \mathrm{A}$ was less than $2 \%$ and only one result deviated from that expected by more than $5 \%$; for the ratio C:A error was materially larger. The variation in transfer factor and $\mathrm{Kco}$ calculated for mixtures $\mathrm{A}$ and $B$ was in the range 3-6\%, with nine results out of $46(20 \%)$ deviating from expected values by more than $5 \%$. The analysers giving the aberrant results were all at least five years old. The error in TLCo was significantly greater than the error in alveolar volume.

\section{Discussion}

The use of small canisters to distribute gas samples proved convenient, economical, and reliable, with a between cans coefficient of variation of $\leqslant 0.6 \%$ for each constituent gas. Only three cans were faulty. In addition, the concentrations found by the reference laboratory were in close agreement with those of the manufacturer. Thus the trial was technically satisfactory and with 50 laboratories participating the conclusions were probably representative of the present position in England and Wales.

Overall the results showed unacceptable inaccuracy of gas analysis in lung function laboratories, but they also showed that the standard of $1 \%$ was attainable if reasonable care was taken. The accuracy of helium analysis was the same as 20 years ago; it was probably better represented by the results for mixtures A and B than for mixture $\mathrm{C}$ since the alveolar oxygen concentration during the measurement of transfer factor is rarely as low as $11 \%$. The accuracy of analysis of carbon monoxide was expected to show improvement because the analyser with a split scale, which was the principal cause of inaccuracy in 1962, is no longer in use. In the event, the variability between laboratories, expressed as the coefficient of variation, was in the range 3-5\%, which was better than the $8 \cdot 6-12 \cdot 6 \%$ found previously. But $86 \%$ of carbon monoxide concentrations fell outside the recommended limit; the figure was $62 \%$ for ratios of concentration. For the calculated transfer factor $20 \%$ of values were in error by more than $5 \%$. This confirms the results of calibration studies using patients. ${ }^{5}$ The technical variability compared unfavourably with the between days variability due to biological factors, which is about $4 \% .^{6}$ The results for analysis of oxygen concentration were also unsatisfactory. The inaccuracies were mostly due to a zero error, which could have resulted from a jolt to the analysers leading to misalignment, and they would have been detected had a calibration check been carried out using 100\% nitrogen. Few laboratories did this routinely.

Both for oxygen and for carbon monoxide the analysers with faulty calibrations were all more than five years old. Age alone, however, was not the explanation since other laboratories obtained good results with old analysers; but faults were not conspicuous with the newer analysers. Since the models were not very different this suggests a lack of maintenance as well as of calibration. None of the errors would have arisen if calibration had been carried out meticulously. The position was worst for carbon dioxide, where the variation between laboratories was large. Here, as for oxygen, there has been a radical change in procedure, with replacement of chemical analysers (Haldane, Lloyd-Haldane, and MicroScholander) by physical ones. The older analysers imposed their own discipline since they demanded careful attention to detail. The techniques were also carried out at relatively few centres, where there was often a research application; this might have led to feedback between scientist and technician, which could have contributed to accuracy. Now that the measurements are made in more centres, accuracy has deteriorated and there is need for greater attention to detail; this would be helped by technical training and by supervision from scientists, either chest physicians with an interest in pulmonary physiology or graduates in physiology

Table 6 Calculated errors in indices of lung function

\begin{tabular}{|c|c|c|c|}
\hline & Absolute value & Variability $(\mathrm{CV}(\%))$ & Number with error $>5 \%$ \\
\hline Alveolar volume* (1) & $\begin{array}{l}\text { (i) } 5.20 \\
\text { (ii) } 5.23\end{array}$ & $\begin{array}{l}1.6 \\
1.8\end{array}$ & $\frac{1}{46}(2 \%)$ \\
\hline $\begin{array}{l}\text { Transfer factor for carbon monoxide } \\
\quad\left(\mathrm{mmol} \mathrm{min}^{-1} \mathrm{kPa}^{-1) *}\right. \\
\text { Respiratory exchange ratio }+\end{array}$ & $\begin{array}{l}\text { (i) } 9.02 \\
\text { (ii) } 5.83 \\
\text { (i) } 0.88 \\
\text { (ii) } 0.70\end{array}$ & $\begin{array}{r}3.1 \\
6.3 \\
10.5 \\
9.3\end{array}$ & $\begin{array}{l}\frac{9}{46}(20 \%) \\
\frac{8}{29}(28 \%)\end{array}$ \\
\hline
\end{tabular}

*Calculated from the results for mixtures $A$ and $B$ for batches $i$ and ii respectively.

+ Calculated from the results for mixtures $B$ and $D$ for batches $i$ and ii respectively. 
or physics with experience of physiological measurement. For the supervision to be effective these people should probably also be interested in and informed about the results.

The Department of Health and Social Security kindly paid for the canisters of test gas and PK Morgan Ltd prepared and distributed them. We are indebted to the University of Newcastle upon Tyne, the Medical Research Council, and the European Economic Community for financial support.

\section{References}

1 Cotes JE, Woolmer RF. A comparison between 27 laboratories of the results of analysis of an expired gas sample. J Physiol 1962;163:36-37P.

2 Cotes JE. Effect of variability in gas analysis on the reproducibility of the pulmonary diffusing capacity by the single breath method. Thorax 1963;18:151-4.

3 Ferris BG. Epidemiology standardisation project. Am Rev Respir Dis 1978;118:1-120.

4 Quanjer PH, ed. Standardised lung function testing. Bull Eur Physiopath Respir 1983;19, suppl 5:1-95.

5 Saunders KB. Current practice in 6 London lung function laboratories. Proc R Soc Med 1977;70:162-3.

6 Cotes JE. Lung function: assessment and application in medicine. 4th ed. Oxford: Blackwell Scientific Publications, 1979. 